\section{Italian promotions defended ...}

SIR - The letter by G.F. Gaetani and A. M. Ferraris (Nature 353, 10; 1991) engendered a violent press campaign by some Italian newspapers, following which the Minister of University and Scientific Research and Technology ordered an inquiry into the proceedings of the committee and its decisions regarding the professorship in question.

As members of that committee, we feel it is now time to provide further information, as the inquiry has now been concluded and has given full approval to both our proceedings and our decisions.

We shall not comment upon the methods used by Gaetani - one of the "losers", as he says - to influence his own academic promotion, neither shall we comment upon the evaluation of the different applicants. But we wish to make it clear that a competition for appointment as a university professor is quite different from academic competitions for scientific awards.

Research work and results are undoubtedly very important in evaluating candidates for professorial positions in a school of medicine. But as regards clinical teaching in haematology, the activity of an applicant needs to be evaluated also in terms of clinical and professional ability, as the basic duty and responsibility of a professor is to teach students how to diagnose and treat a disease and how to care for patients. Such fundamental aspects of the problem should not be ignored.

MiCHELE BACCARANI * (Professor of Haematology Udine University,), GIANLUIGI CASTOLDI (Professor of Haematology, Ferrara University), GIUSEPPE PAPA (Professor of Haematology, Rome University (Tor Vergata)), GIUSEPPE PERONA (Professor of Haematology, Verona University) SANTE TURA (Professor of Haematology, Bologna University)

\section{... and attacked}

SIR - Promotion to a full professorship in paediatrics in Italian medical schools seems to suffer from more serious problems than does a similar appointment in haematology'. A committee of five full professors of paediatrics, after three years of discussion and the replacement of two of its members, has just appointed 25 new professors from among 74 candidates ${ }^{2}$.

The explanation put forward by Gaetani and Ferraris' for haematology candidates seems to apply in an even more extreme sense here. Of the paediatrics candidates, five of the winners averaged 2.2 winners in the Science Citation Index (two having published no papers in international journals) whereas five of the losers averaged 103, with a remarkable peak of 302 .

The Minister for University Affairs decided not to validate these results and the same committee was asked to reconsider the same list of candidates. After two months, the results were confirmed. After a further three months, the $\mathrm{Na}$ tional University Council (CUN) is to confirm the appointment of 24 new professors, casting doubts on only one of the five candidates with few citations. This means that the minister must now either accept the decision on the 24 winners or appoint a completely new committee to reconsider all 74 candidates.

It is not our intention to criticize the Italian system of academic promotion in general; it provides good results in many fields of pure science, including physics, where Italian work is well established internationally. But although scientific output should not, of course, be the only criterion for academic promotion, there should be a threshold below which no candidate is acceptable.

The case of the paediatrics professorships is not an isolated one, and may indicate systematic nepotism in the management of appointments to clinical professorships in Italian medical schools: candidates for paediatrics professorships, ten are allievi (pupils is not an adequate translation) of the five members of the committee, and all of them were appointed.

The main problem is that decisionmaking committees and university officials are not held responsible for their mistakes. Substantial portions of research grants and all new academic posts are distributed among universities, faculties and departments without consideration for the quality of their science or their teaching. This is not the situation elsewhere in Europe or in the United States. As a consequence, Italian departments and institutes have no incentive for high standards of science, and the appointment of the best scientists and scholars is not encouraged.

We should like in conclusion to suggest that the Italian system of academic promotion be changed to follow more closely the criteria used in other European unishould be responsible for specifying the scientific and academic requirements for a vacant position and should be allowed to nominate at least three candidates. All the candidates, who need not be Italian, should submit their curricula vitae and reprints of their best publications to an international panel of referees. The committee should then say (1) whether at least three candidates meet the scientific and academic threshold qualification and versities. The departments concerned
(2) who among the candidates best meets the department's requirements.

FERNANDO AIUTI* (professor of clinical immunology and allergy, University of Rome 'La Sapienza'), CARlo BARONI (professor of pathology, University of Rome 'La Sapienza'), ANTONIO CAO (professor of paediatrics, University of Cagliari), ANTONIO FANTONI (professor of molecular genetics, University of Rome 'La Sapienza')

1. Gaetani, G. F. \& Ferraris, A. M. Nature 353, 10
(1991).
2. Aiuti, F., Baroni, C., Cao, A. \& Fantoni, A. Lancet ii, 1387
(1991).
*Full address: Policlinico Umberto 1, 00161 Rome, Italy

SIR - Further to your continuing correspondence on Italian academic appointments, I wish to describe what seems to be an entirely novel way of constituting the commissions that evaluate applicants for tenured academic positions. My story also illustrates the remarkable flexibility now required of those eventually appointed.

Some time ago, the physics department of this small university in central Italy announced a vacancy for an associate professor in atmospheric physics; we have an active group in stratospheric modelling and measurement involved in several international research programmes. The several active workers in this field are concentrated at three or four universities, but in the whole of Italy there are only one full professor and one associate professor of atmospheric physics and one associate professor of meteorology.

On this occasion, an entirely novel way of choosing the evaluation commission was devised. For these purposes, all disciplines are grouped together on the basis of some kind of affinity; the subgroup including atmospheric physics (D043) is entitled Atmospheric Physics, Oceanography and Navigation, and belongs to the major grouping of Earth Sciences (not physics), including such subgroups as General and Spherical Astronomy, Terrestrial Physics and Limnology.

The evaluation commission was chosen in two steps; first, a pool of potential members was chosen by lot from among all professors and associate professors in the Earth sciences, after which the same people voted to elect a subset from the pool. It is useless to speculate about who invented this system, but the effect is evidently to favour the large schools, in this case professors of terrestrial physics, who happen to be concentrated in a few universities.

Even if the lottery were above board (which nobody believes), the result would have been that candidates would probably have been from the same large schools, whose votes then ensure the 
election of the same people.

Proofs of this positive feedback are easily provided. Of 18 candidate full professors, seven were from the same southern university (Naples) and 13 were professors of terrestrial physics. It is relevant that terrestrial physics professors in Italy are mostly in solid-Earth geophysics, especially in seismology and volcanology (which explains why they are concentrated in southern Italy). Some years ago, a very good candidate for a full professorship in terrestrial physics was rejected on the grounds that his research articles (more than 40, in international refereed journals) in atmospheric physics were "not pertinent".

In the recent competition in the D043 subgroup, there were three vacancies to be filled - our own post in atmospheric physics, one in oceanography and limnology from another university and one at the Institute of Navigation of the University of Naples. The commission formed by lottery and election consisted of three full professors and one associate from the University of Naples and one associate from the other university with a vacancy to fill. None of them has ever published a paper on atmospheric physics, meteorology or the like. Two separate protests on this score by the president of the National Institute of Geophysics were, as usual, ignored by the Ministry of University Research and Technology.

What other countries would expect from such a commission I do not know, but in Italy we quickly saw an obvious flaw; this university, which had prompted the competition by announcing a vacancy, would be in trouble. Indeed, soon after the commission was formed, we knew the name of the seismologist who would win the position as associate professor of atmospheric physics.

In this case, the commission had to decide on the basis of publications, other evidence and a public lecture on a topic of the candidate's choice. Among the 12 applicants considered at the last stage were three in atmospheric science, one of whom had spent ten years at an international institution in Europe, and had acquired an international reputation for his work there. Six weeks after the last of the public lectures, the commission announced its decision. Of the three vacancies, the two at the other universities were filled by local candidates, but the vacancy in atmospheric physics at this university was filled by a seismologist (whose name we knew from the beginning) from the same southern university providing four out of the five commissioners.

Formally, the university has the right to decline to appoint the nominee, on the grounds that he is not what it was looking for, but the ministry has the right to send him anyway. There is also a slight chance that the Commission on Universities might intervene, but it is empowered to do so only if there have been formal irregularities; provided that there have been no obvious irregularities, a university could have asked for a cardiologist and been sent a dentist instead.

Atmospheric physics is now growing in Italy in response to questions such as that of global warming, but atmospheric scientists are in danger of becoming an endangered species. Yet the ministry and the Commission on Universities have recently decided that atmospheric physics should be an essential part of the physics curriculum. It is doubtful that this goal can be achieved if tenured appointments are decided by power and not competence.

Universita degli Studi l'Aquila,

Guido VISCONTI

Atmospherics Group,

67010 Coppito (L'Aquila),

Italy

\section{Drug approvals}

SIR - The survey by the US Pharmaceutical Manufacturers Association (PMA) of new biotechnology products that have been approved or are in the pipeline (see Nature 353, 591; 1991) is interesting, but we at the Food and Drug Administration (FDA) were disturbed by its interpretation of the projected rate of marketing approval for new biotechnology products by the FDA's Center for Biologics Research and Review (CBER).

PMA has calculated FDA's rate of approval for new biotechnology products by dividing the total number of products approved by the total time elapsed since the first product was approved (in 1982), which yields a value of some 1.6 approvals a year. They then reason that because their survey reports 21 products now awaiting approval (although FDA's records indicate the number is closer to 30 ), it would take FDA's CBER 13 years to approve these products.

The fallacy of this mathematical sleight-of-hand is that it ignores the fact that for much of the past decade there were very few products in the pipeline and that they were approved rapidly after the marketing applications were received by FDA. Moreover, at least 4 of the 21 are currently ineligible for approval because of marketing exclusivity granted to other similar products under the provisions of the US Orphan Drug Development Act.

Finally, PMA's own data reveal that "FDA required an average review time of 21.4 months" to approve biotechnology therapeutics compared to the mean approval time for other new molecular entities of 31.8 months cited in PMA's "New Drug Approval in 1990". Thus,
FDA has, in fact, approved new biotech products an average of ten months more quickly than for other non-biotech drugs, with all the advantages to manufacturers - and, more important, to patients - that implies.

HENRY I. MiLler (Director)

Office of Biotechnology, Food and Drug Administration, Rockville, Maryland 20837, USA

\section{Artists' offspring}

SIR - The possibility that artists have more sons than daughters is suggested by a count of the following sources:

(1) those for whom the relevant information is included in Who's Who in Art, 24 th $^{2}$ edition ${ }^{1}$ (which covers artists, designers, craftsmen, critics, writers, teachers and curators);

(2) those mentioned in the obituary section of the above publication for whom the relevant information can be found in Who's Who in Art, 19th edition ${ }^{2}$;

(3) those artists and craftsmen in the 1985 to 1990 volume of The Annual Obituary $^{3}$ for whom relevant details can be found therein. (Sons and daughters of artists in both (2) and (3) are counted once only.)

The total numbers of sons and daughters, including deceased children but excluding stepchildren, are 1,834 and 1,640 respectively, giving a sex ratio of 1.1183. A control experiment was carried out involving a count of the sons and daughters recorded in the general Who's $W h o^{4}$, the aim being to expose any male (or female) bias in reporting offspring: the sex ratio for the first 4,002 offspring was $2,046 / 1,956=1.0460$. This is close to the 1.0534 ratio which applies to British births generally (based on statistics of 723,093 births published in the 1987 Demographic Yearbook ${ }^{1}$ ) and suggests that there may be no significant male bias in reporting offspring in biographical reference books. Comparing then the sex ratio of the artists's children in (1) - (3) against the sex ratio for the British births generally, the $\chi^{2}$ value is 3.0173 , giving a probability $P=0.085$ approximately. Further work on correlations between parentage and the sex ratio of offspring appears desirable.

49 Curzon Avenue,

R. A. BECK

\section{Stanmore,}

Middlesex HA7 2AL, UK

\footnotetext{
1. Who's Who in Art (24th edn) (Art Trade Press, Havant, Hants, 1990).

Who's Who in Art (19th edn) (Art Trade Press, Havant, Hants, 1980).

3. The Annual Obituary Vols 1985-88 (ed. Burgess, P.) Vols 1989-90 (ed. Andrews D.) (St James Press, Chica go and London).

Go and London).

5. 1987 Demographic Yearbook, 350 (United Nations. New
} York 1989). 